\title{
A Study of Non-Scarring Diffuse Alopecia
}

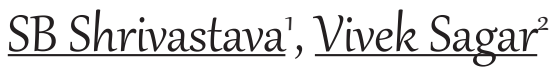 \\ ${ }^{1,2} \mathrm{Dr}$ Baba Saheb Ambedkar Medical College \& Hospital, Govt. of NCTD of Delhi, Rohini, Delhi. \\ DOI: https://doi.org/10.24321/2349.7181.201808
}

\begin{abstract}
Paucity of reports on non-scarring diffuse alopecia in women from this part of the world led us to take up this study. We examined 200 consecutive cases of non-scarring diffuse alopecia in women who attended the skin OPD of a tertiary level urban hospital to find out the different types of diffuse hair loss, their clinical profile, key diagnostic features and etiological factors associated with them. Chronic telogen effluvium (CTE), female pattern hair loss (FPHL) and telogen effluvium (TE) were found to be the most common types of diffuse hair loss, seen in $71(35.5 \%), 70$ (35\%) and $46(23 \%)$ patients, out of a total of 200 . These three (CTE, FPHL and TE) together accounted for $93.5 \%$ (187/200) of total cases of non-scarring diffuse alopecia in women. Excessive, alarming, diffuse shedding coming from a normal-looking head with plenty of hair and without an obvious cause was the hallmark of CTE. FPHL was presented as gradual diffuse hair loss with thinning of central scalp and intact hair line (Ludwig type), widening of central parting line with or without a Christmas tree pattern (Olsen type), or as fronto-temporal/bi-temporal recession with or without loss at vertex (Hamilton type/Male type). An abrupt onset and rapid, diffuse, excessive shedding of normal club hair, usually seen 2-3 months after a triggering event was the typical presentation of TE cases. High fever, postpartum hemorrhage and emotional stress were the common triggers associated with TE. Abnormal thyroid functions $(23 / 200,11.50 \%)$ and anemia $(78 / 200,39 \%)$ were noted in a significant number of cases of diffuse hair loss, making it mandatory to investigate them in all cases of diffuse hair loss.
\end{abstract}

Keywords: Alopecia, Diffuse hair loss, Telogen effluvium

\section{Introduction}

Women presenting with diffuse hair loss is a very common and challenging problem for dermatologists. There are various types of diffuse hair loss (Table 1), the common ones are telogen effluvium (TE), female pattern hair loss (FPHL), and chronic telogen effluvium (CTE). These three together accounts for most of the cases of non-scarring diffuse hair loss. ${ }^{1}$ The exact prevalence of these three conditions varies in the limited reports available, and identifying them is an additional challenge. There are only a few studies conducted in India and other countries exploring the prevalence of various types of diffuse hair loss in women, and the etiological factors associated with them. This study has been conducted with the aim to find out the prevalence of various types of non-scarring diffuse hair loss among Indian women and to delineate their key diagnostic features and associated etiological conditions.

Table 1.Causes of Diffuse Alopecia (Non-Scarring)

\begin{tabular}{|c|}
\hline Telogen effluvium (TE) \\
\hline Female pattern hair loss (FPHL) \\
\hline Chronic telogen effluvium (CTE) \\
\hline Anagen effluvium \\
\hline Loose anagen hair syndrome \\
\hline Diffuse type of alopecia areata \\
\hline Congenital atrichia, Congenital hypotrichosis, and Hair shaft abnormalities (Hair breakage, Unruly hair) \\
\hline
\end{tabular}

Corresponding Author: Dr. Vivek Sagar, Dr Baba Saheb Ambedkar Medical College \& Hospital, Govt. of NCTD of Delhi, Rohini, Delhi. E-mail Id: viveksagar_sagar@yahoo.co.in

Orcid Id: https://orcid.org/0000-0003-3241-8498

How to cite this article: Shrivastava SB, Sagar V. A Study of Non-Scarring Diffuse Alopecia. J Adv Res Med 2018; 5(2): 13-18. 


\section{Materials and Methods}

This was a prospective observational study carried out on patients in the skin OPD of a tertiary-level urban hospital. We studied 200 consecutive women who attended the skin OPD with the complaints of loss of hair from the scalp. The patients were classified into various types of non-scarring diffuse hair loss based on their distinguishing features. ${ }^{1}$ All patients underwent laboratory screening including $C B C$, urine for routine and microscopic examination, and thyroid function test. Biopsy was undertaken only in rare cases when the clinical diagnosis was in doubt and the patient consented for it. Patients with congenital alopecia and cicatrial alopecia were excluded from the study.

\section{Results}

The results of the study are summarized in Tables 2, 3, 4 and 5 . Out of the total 200 patients, 70, 46, 71, 1, 1 and 11 were diagnosed as FPHL, TE, CTE, diffuse alopecia areata (AA), anagen effluvium and CTE/FPHL, respectively (Table 2 ). In the later 11 cases, no definitive diagnosis, as to whether they were CTE or FPHL, was possible. FPHL, TE and CTE together accounted for $93.5 \%$ (187/200) of total cases. Their clinical profile and associated conditions are depicted in Table 3 and Table 4 respectively. Their characteristic features, recorded in Table 5, are explained below.

FPHL: Three types of FPHL were recorded:

- The first one was characterized by gradual diffuse hair loss with thinning of central scalp and intact hair line (Ludwig type, Fig. 1). It was the most common type accounting for $51.42 \%$ (36/70) cases of FPHL.

- Second showed widening of central parting line or a Christmas tree pattern (Olsen type, Fig. 2). It was recorded in $42.85 \%$ (30/70) of FPHL cases.

- The third type revealed fronto-temporal/bi-temporal recession or loss at vertex (Hamilton type/male type,
Fig. 3). It was found in only $5.71 \%(4 / 70)$ of cases.

TE: An abrupt onset and rapid, diffuse, excessive shedding of normal club hair, usually seen $2-3$ months after a triggering event was the typical presentation of TE cases. High fever, postpartum hemorrhage and emotional stress were the common triggers associated with TE (Table 4).

CTE: Excessive, alarming, diffuse shedding coming from a normal-looking head with plenty of hair and without an obvious cause were the features found in CTE. Usually, a handful of hair is displayed by the patient to corroborate the complaint of excessive shedding.

AA: Although abrupt onset with diffuse hair loss mimic TE, yet the presence of exclamation point hair, dystrophic hair, eyebrow alopecia, nail pitting, yellow dots on dermoscopy, clinched the diagnosis of AA in the lone case of AA recorded in this study.

Anagen Effluvium: Acute generalized loss of hair was noticed in one patient while the patient was on chemotherapy for breast cancer. The examination of hair revealed anagen hair.

The mean age of the subjects was $35,28,31,25,40$, and 32 years for FPHL, TE, CTE, diffuse alopecia areata (AA), anagen effluvium and CTE/FPHL respectively. The mean age of total patients was 31.5 years, with a range of 15 to 67 years. Anemia (hemoglobin $<12 \mathrm{gm}$ ) was found in 78 out of 200 (39\%) patients. The number of patients having hemoglobin less than $12 \mathrm{gm}$ along with their percentage in various types of hair loss is given in Table 3. Abnormal thyroid functions were recorded in $11.5 \%$ cases $(23 / 200)$. Out of these 23 patients with abnormal thyroid function test, 21 were having hypothyroidism. So, hypothyroidism alone accounted for $10.5 \%$ of total cases. A total of 88 out of 200 patients (39\%) had associated cutaneous or systemic disorders. These are mentioned in Table 4.

Table 2.Types of Non-Scarring Diffuse Alopecia Recorded in Women

\begin{tabular}{|c|c|c|}
\hline Types of Hair Loss & Number of Patients & Percentage \\
\hline FPHL & 70 & 35 \\
\hline TE & 46 & 35.5 \\
\hline CTE & 71 & 0.5 \\
\hline AA (diffuse) & 1 & 0.5 \\
\hline Anagen effluvium & 1 & 5.5 \\
\hline CTE/FPHL & 11 & 100 \\
\hline Total & 200 & 23 \\
\hline
\end{tabular}


Table 3.Profile of Patients of Diffuse Alopecia

\begin{tabular}{|c|c|c|c|c|}
\hline Type of Hair Loss & $\begin{array}{c}\text { Mean Age of } \\
\text { Patients in } \\
\text { Years }\end{array}$ & $\begin{array}{c}\text { Number of } \\
\text { Patients with Hb } \\
<12 \text { gm (with \%) }\end{array}$ & $\begin{array}{c}\text { Number of Patients } \\
\text { with Abnormal Thyroid } \\
\text { Function (with \%) }\end{array}$ & $\begin{array}{c}\text { Number of } \\
\text { Associated } \\
\text { Disorders (with \%) }\end{array}$ \\
\hline FPHL $(n=70)$ & 35 & $22(31.42)$ & $6(8.57)$ & $30(42.85)$ \\
\hline TE $(n=46)$ & 28 & $18(39.13)$ & $5(8.86)$ & $32(69.56)$ \\
\hline CTE $(n=71)$ & 31 & $30(42.25)$ & $11(15.49)$ & $22(30.95)$ \\
\hline AA ( $n=1)$ & 25 & $1(50)$ & Nil & $1(50)$ \\
\hline Anagen effluvium $(n=1)$ & 40 & Nil & Nil & $1(100)$ \\
\hline CTE/FPHL $(11)$ & 32 & $4(36.36)$ & $23(11.50)$ & $2(18.18)$ \\
\hline Total patients $(n=200)$ & 31.5 & $78(39)$ & & $88(44)$ \\
\hline
\end{tabular}

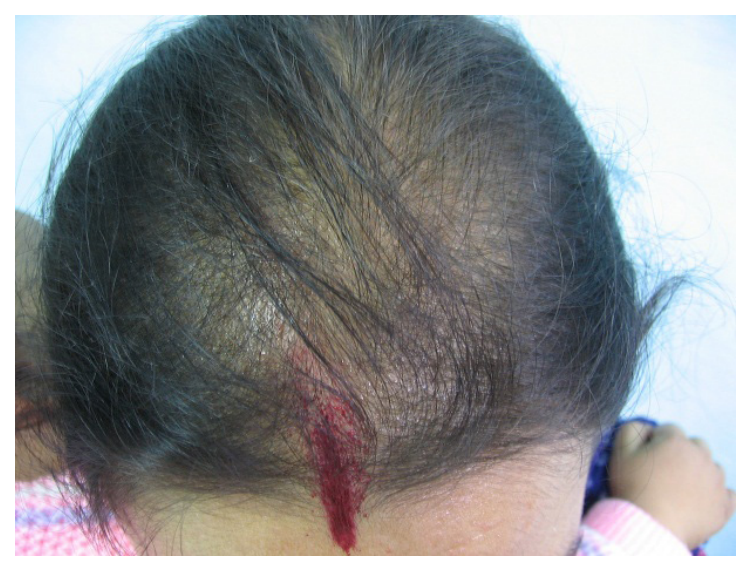

Figure 1.Female Pattern Hair Loss (Ludwig Type) Showing Central Thinning with Intact Hair Line

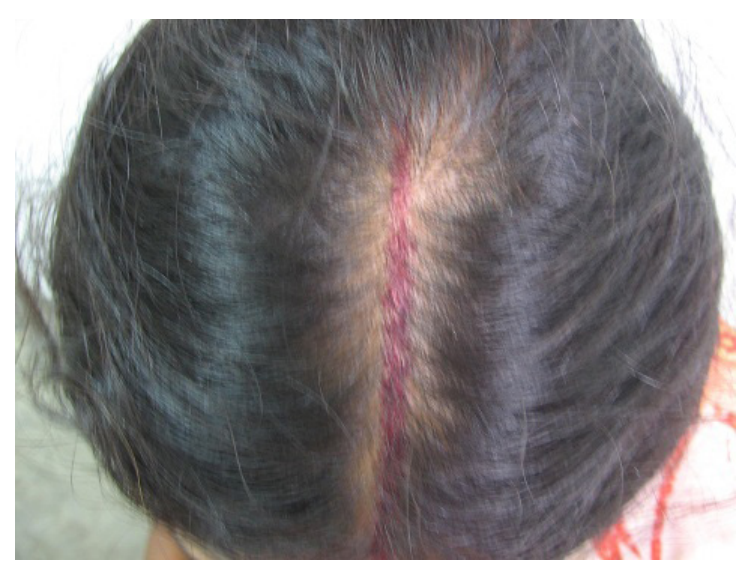

Figure 2.Female Pattern Hair Loss (Olsen Type) Showing Thinning of Central Parting Hair Line

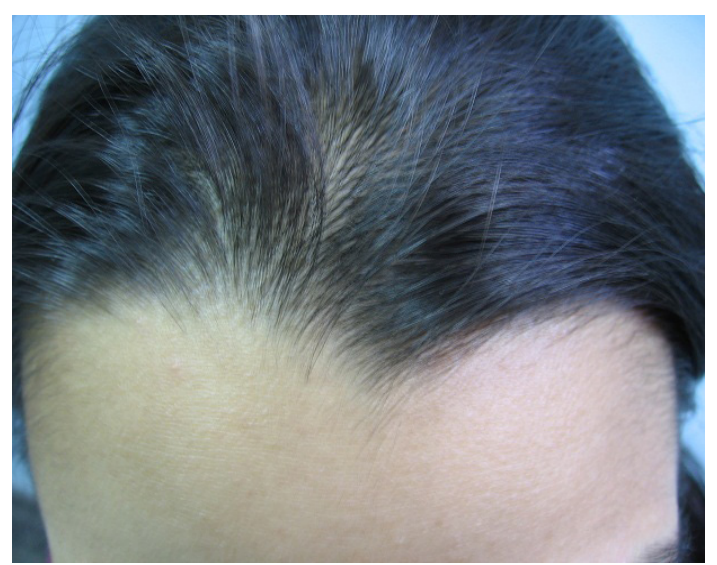

Figure 3.Female Pattern Hair Loss (Hamilton Type or Male Pattern Type) Showing Bi-temporal Recession 
Table 4.Triggering factors and diseases (with numbers of patients) associated with TE, FPHL and CTE

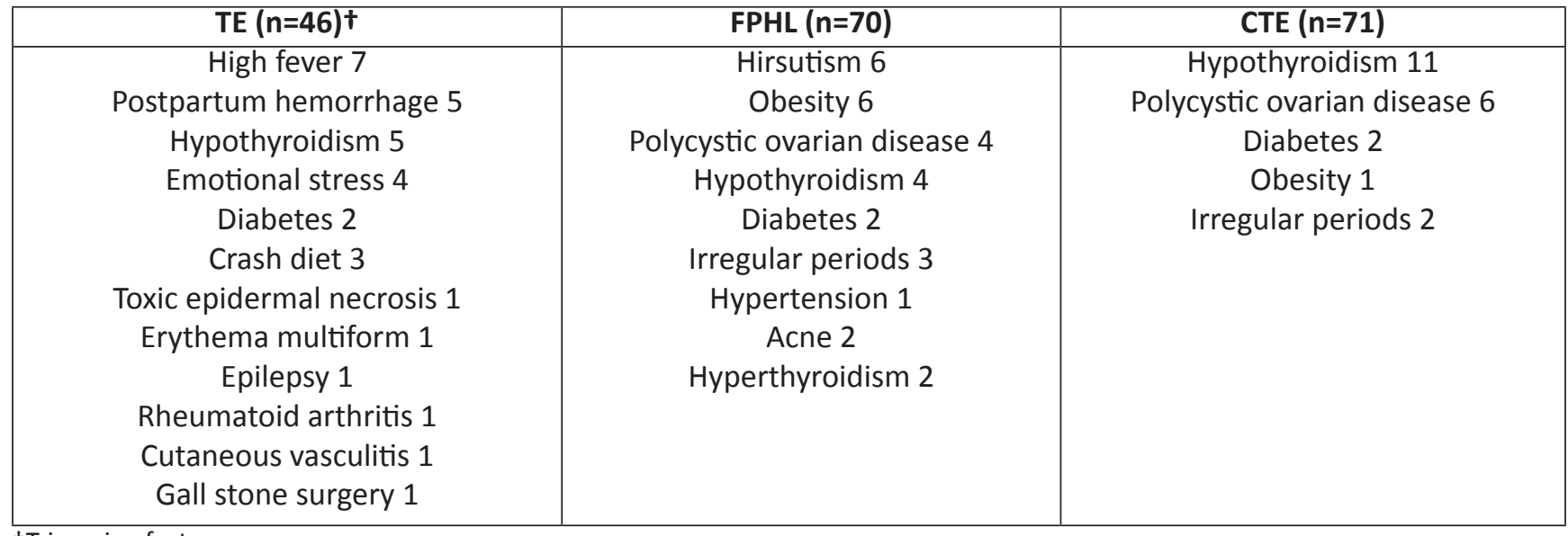

Triggering factors

Table 5.Key Differentiating features recorded in TE, FPHL and CTE

\begin{tabular}{|c|c|c|c|}
\hline Features & TE & FPHL & CTE \\
\hline Onset & Abrupt & Gradual & Abrupt \\
\hline Shedding & $\begin{array}{l}\text { Excessive, diffuse, and } \\
\text { generalized }\end{array}$ & Minimal & $\begin{array}{l}\text { Excessive, alarming } \\
\text { (hallmark) }\end{array}$ \\
\hline $\begin{array}{l}\text { Pattern of hair } \\
\text { loss }\end{array}$ & Diffuse hair loss & $\begin{array}{c}\text { Sparse hair at central scalp area or } \\
\text { at parting line }\end{array}$ & Diffuse hair loss \\
\hline Thinning & Diffuse thinning & $\begin{array}{l}\text { Central thinning with or without } \\
\text { widened central parting line }\end{array}$ & $\begin{array}{l}\text { Absent, if present, it is } \\
\text { all over. H/o reduced } \\
\text { ponytail volume }\end{array}$ \\
\hline $\begin{array}{l}\text { Bi-temporal } \\
\text { recession }\end{array}$ & Absent & $\begin{array}{l}\text { Mild to moderate and only } \\
\text { in male-type FPHL, which is } \\
\text { uncommon }\end{array}$ & $\begin{array}{l}\text { Mild to moderate and } \\
\text { common }\end{array}$ \\
\hline Miniaturized hair & Absent & Present in many cases & Absent \\
\hline Hair pull test & $\begin{array}{c}\text { Strongly present throughout } \\
\text { the scalp }\end{array}$ & $\begin{array}{l}\text { Usually absent, if present, only at } \\
\text { central scalp }\end{array}$ & $\begin{array}{l}\text { Present throughout in } \\
\text { active phase }\end{array}$ \\
\hline Trichogram & $\begin{array}{l}\text { Significantly reduced anagen: } \\
\text { telogen ratio ( } \mathrm{A}: \mathrm{T} \text { ratio) }\end{array}$ & $\begin{array}{l}\text { A:T ratio is normal or slightly } \\
\text { reduced }\end{array}$ & $\begin{array}{l}\text { Reduced A:T ratio in } \\
\text { active phase }\end{array}$ \\
\hline Dermascopy & No variation in shaft diameter & $\begin{array}{c}\text { Marked variation in shaft } \\
\text { diameter. Miniaturized follicles } \\
\text { (hallmark) }\end{array}$ & $\begin{array}{l}\text { No significant } \\
\text { variation. No } \\
\text { miniaturization }\end{array}$ \\
\hline $\begin{array}{l}\text { Biopsy done only } \\
\text { in few cases }\end{array}$ & $\begin{array}{l}\text { Increase in percentage of } \\
\text { telogen hair }(11-30 \%), \\
\text { terminal:vellus (T:V) ratio } \\
\text { normal, no miniaturization }\end{array}$ & $\mathrm{T}: \mathrm{V}$ reduced ( $<4: 1$ is diagnostic) & $\mathrm{T}: \mathrm{V}$ ratio normal $(8: 1)$ \\
\hline
\end{tabular}

\section{Discussion}

CTE, FPHL and TE are the most common causes of nonscarring alopecia in women. Together they account for most of the cases of diffuse hair loss..$^{1-4}$ In this study also, these three entities accounted for $93.5 \%$ (187/200) of total cases. The prevalence of FPHL and CTE in this study was almost equal in percentage term, 35\% for FPHL and 35.5\% for CTE, while TE was seen in $23 \%$ of cases. The prevalence of these different types of alopecia varies in different studies and a comparison between prevalence studies is hampered by the lack of universally accepted criteria for diagnostic definition of these disorders. Therefore, their differentiating diagnostic features, recorded in the study and depicted in Table 5, are explained below.

FPHL is distinguished by patterned hair loss, presence of miniaturized/vellus hair (short thin hair $<3 \mathrm{~cm}$ and a shaft diameter of $<.03 \mathrm{~mm}$ ), hair shaft diameter diversity better seen during dermoscopy, absent or mild shedding, usually a negative hair pull test and a diagnostic $\mathrm{T}$ : $\mathrm{V}$ ratio of $<4: 1$ (normal is 8:1). 
CTE, first described by Whiting in 1996, is an idiopathic distinct entity characterized by an excessive alarming diffuse shedding of hair in females aged 30-60 years, with a prolong fluctuating course and near-normal histology. ${ }^{5}$ Reduction in the volume of their ponytail thickness without obvious diffuse thinning, a positive hair pull test at all sites of scalp (vertex, occipital, and sides) in active phase, absence of patterned loss and miniaturization of hair (the two features seen in FPHL) and a near normal histology except for slight increase in the telogen hair follicles are other differentiating features noted in patients of CTE. These are consistent with the findings noted by Whiting. ${ }^{5}$

TE: Abrupt onset, rapid diffuse generalized shedding of hair, usually 2-3 months after a triggering and shedding of nearly 100-1000 hair/day was noted. A strongly positive hair pull test where more than $10 \%$ of the total hair pulled were easily extracted from any part of the scalp in the acute phase, a trichogram (forcible complete hair pluck of 40-60 hair) showing significant reduction in anagen:telogen ratio with $>15 \%$ to $25 \%$ of the plucked hair were telogen hair (in acute phase) and large number of short-tip pointed regrowing hair in the absence of hair diameter variability on dermoscopy, were recorded. These findings were noted in many studies. ${ }^{6-11}$ In diffuse $A A$, which is quite rare, presence of exclamation point hair, dystrophic hair, patchy hair loss elsewhere over the body, nail pitting, yellow dots on dermoscopy and presence of peribulbar inflammatory lymphocytic infiltrate (swarm of bees) on histopathology were the key distinguishing features recorded in this and other studies. ${ }^{12,13}$ In anagen effluvium, history is very important. It is generally seen during chemotherapy and is characterized by shedding of anagen rather than telogen hair which can be identified on examination of hair.

A number of triggering factors were identified for patients of TE (Table 4). Common among them were fever (7/46, $15.21 \%$ of TE cases), postpartum hemorrhage (5/46, 10.86\%) and emotional stress (4/46, 8.69\%). Hypothyroidism was detected in 5/46 (10.86\%) cases. These triggering factors were recorded in other studies also. ${ }^{6,14}$ In 14 out of 46 (30.43\%) cases of TE, no triggering factor or associated condition was noted. A large number of associated conditions were noted in FPHL cases. Common among them were hirsutism $(6 / 70,8.57 \%)$, obesity $(6 / 70,8.57 \%)$, polycystic ovarian disease $(4 / 70,5.71 \%)$, hypothyroidism $(4 / 70,5.71 \%)$ and diabetes $(4 / 70,5.71 \%)$. Abnormal hormone profiles were observed in $67 \%$ of the patients with alopecia alone in one study. ${ }^{15}$ Androgens were not estimated in this study, but $30 \%(21 / 70)$ of cases of FPHL had features suggestive of hyperandrogenism, such as hirsutism, polycystic ovarian syndrome, obesity, acne and irregular periods.

Abnormal thyroid functions and anemia were noted in a significant number of cases of diffuse hair loss (Table 3 ).
Abnormal thyroid functions were found in 32 out of 200 cases $(11.5 \%)$ and anemia in 78 cases (39\%). Anemia, especially iron-deficiency anemia, and thyroid hormone disorders are the two common conditions often associated with diffuse hair loss, and most of the time, there are no apparent clinical features to suggest them, so these must be investigated in all cases of diffuse hair loss in women. ${ }^{16}$

\section{Conclusion}

Chronic telogen effluvium (CTE), female pattern hair loss (FPHL), and telogen effluvium (TE) are the most common causes of non-scarring diffuse alopecia in women. They are identified with their characteristic features which should be kept in mind while approaching a patient of diffuse hair loss.

\section{Conflict of Interest: None}

\section{References}

1. Shrivastava SB. Diffuse hair loss in adult female: Approach to diagnosis and management. Indian J Dermatol Venereol Leprol 2009; 75: 20-28.

2. Sinclair RD, Banfield CC, Dawber RP. Diffuse hair loss. In: Sinclair RD, Banfield CC, Dawber RP, editors. Handbook of Diseases of the Hair and Scalp. UK: Blackwell Science Ltd 1999; 64-74.

3. Rustom A, Pasricha JS. Causes of diffuse alopecia in women. Indian J Dermatol Venereol Leprol 1994; 60: 266-71.

4. Jain VK, Kataria U, Dayal S. Study of diffuse alopecia in females. Indian J Dermatol Venereol Leprol 2000; 66: 65-68.

5. Whiting DA. Chromic telogen effluvium: Increased scalp hair shedding in middle-aged women. J Am Acad Dermatol 1996; 35: 899-906.

6. Kligman AM. Pathologic dynamics of hair loss. Telogen effluvium. Arch Dermatol 1961; 83: 175-98.

7. Thiedke CC. Alopecia in women. Am Fam Physician 2003; 67: 1007-14.

8. Shapiro J, Wiseman M, Lui H. Practical management of hair loss. Can Fam Physician 2000; 46: 1469-77.

9. Shapiro J, Lui H. Common hair loss disorders. In: Hordiwnsky MK, Sawaya ME, Scher RK, editors. Atlas of Hair and Nails. Churchill Livingston; 2000; 91-103.

10. Dhurat R. Phototrichogram. Indian J Dermatol Venereol Leprol 2006; 72: 242-44.

11. Tosti A, Piraccini BM. Telogen effluvium. In: Tosti A, Piraccini BM, editors. Diagnosis and Treatment of Hair Disorders. UK: Taylor and Francis 2006; 57-61.

12. Sperling L. Evaluation of hair loss. Current Problems in Dermatology 1996; 8: 2-30.

13. Ross EK, VincenziC, Tosti A. Videodermoscopy in the evaluation of hair and scalp disorders. J Am Acad Dermatol 2006; 55: 799-806.

14. Headington JT. Telogen effluvium: New concepts and views. Arch Dermatol 1993; 129: 356-63. 
15. Vexiau P, Chaspoux $C$ et al. Role of androgens in female-pattern androgenetic alopecia, either alone or associated with other symptoms of hyperandrogenism. Archives of Dermatological Research 2000; 292(12): 598-604.

16. Trost LB, Bergfeld WF, Calogeras E. The diagnosis and treatment of iron deficiency and its potential relationship to hair loss. J Am Acad Dermatol 2006; 54: 824-44.

Date of Submission: 2018-04-30 Date of Acceptance: 2018-05-01 